\title{
A methodology for the development of innovation clusters: application in the health care sector
}

Benjamin Zimmer ${ }^{1,2,}$, Julie Stal - Le Cardinal ${ }^{1}$, Bernard Yannou ${ }^{1}$, Gilles Le Cardinal $^{3}$, François Piette $^{2,4}$, Vincent Boly ${ }^{5}$

${ }^{1}$ Ecole Centrale Paris, Laboratoire Genie Industriel - Grande Voie des vignes, 92290 ChatenayMalabry, France

Benjamin.Zimmer@ecp.fr, Julie.Le-Cardinal@ecp.fr, Bernard.Yannou@ecp.fr

${ }^{2}$ Hôpital Charles-Foix - 7, avenue de la République, 94200 Ivry-sur-Seine, France Francois.Piette@cfx.ap-hop-paris.fr

${ }^{3}$ Université de Technologie de Compiègne, Laboratoire Sciences Humaines - Centre Pierre Guillaumat, Bât. 1, Rue du Docteur Schweitzer, 60200 Compiègne, France

Gilles.Le-Cardinal@utc.fr

${ }^{4}$ Université Pierre et Marie Curie, Faculté de Médecine - 15 Rue Ecole De Médecine, Paris, France

${ }^{5}$ Université de Nancy, ERPI (Equipe de Recherche sur les Processus Innovatifs) - 8, rue Bastien Lepage 54010 Nancy Cedex, France

Vincent.Boly@ensgsi.inpl-nancy.fr

*Corresponding author. Benjamin Zimmer, Email: Benjamin.Zimmer@ecp.fr

Keywords: innovation cluster; innovation management; health care; project owner; conflict resolution; cluster development; value creation; industrial policy

\begin{abstract}
For more than 10 years, the French State and administrative regions have pursued economic development policies that stimulate all forms of innovation and encourage strategic market alliances of the economic stakeholders of a region. These "cluster" policies aim to create ecosystems that are conducive to innovation and promote the emergence of collaborative organizations. Among these innovation clusters, we are concerned with those in the health care field pertaining to aging and autonomy. Business models and action plans for these collaborative organizations are neither easy to define nor easy to stabilize and reinforce, because of the diversity of stakeholders with multiple expectations involved. This paper presents an application of the FAcT-Mirror method in the Sol' iage ${ }^{1}$ innovation cluster during its development stage. We demonstrate that the FAcT-Mirror method is particularly efficient and effective during the

\footnotetext{
${ }^{1}$ http://www.soliage.com/english-version/
} 
process of transformation from the emerging stage (stage of intention) to the development stage (stage of action) for a health care cluster to collectively produce common tools (definitions, strategy, working groups, and action plans).

\section{Introduction}

Innovation is a necessary condition to remain competitive and to survive in a business or company. To innovate, the company must constantly look for new knowledge, both internally and externally. Boschma and Ter Wal (2007) state that innovation is achieved through the acquisition of knowledge outside the company. In other words, the company must be able to open itself up to other market stakeholders on the cognitive, relational, institutional, and organizational dimensions, whatever their local roots are. One innovation policy tool to achieve this objective is for the company to actively participate in an innovation cluster. According to Hamdouch (2008), this issue has been of growing interest for the past 20 years, both at a regional economics level and at a national industrial policy level, as well as in terms of academic research (in economics, economic sociology, and strategic management). Building on the success of clusters in the U.S. high-technology sectors, most of the European countries and Japan have reconsidered their industrial policy and traditional innovation to shift toward development mentalities and also toward territorialized competitiveness, as demonstrated by Japanese initiatives (Depret and Hamdouch, 2009 ; Yoshida, 2005).

According to Hamdouch (2008), an innovation cluster consists of "a set of organizations and institutions, defined by their nature and location, which interact formally and informally through diverse inter-organizational and inter-individual networks and contribute to the implementation of innovations in a business sector, i.e., in a domain defined by characteristic fields of knowledge, skills and technologies."

An innovation cluster must respond to issues linked to competitiveness among countries and regions and to the emergence of new markets and opportunities in situations that are growing in complexity. It must stimulate and encourage research and development of solutions adapted to latent needs in all industrial sectors by increasing the encounter and cooperation opportunities among stakeholders who are part of the same value chain.

Among these innovation clusters are those in the health care domain, which are particularly complicated to induce into emergence and develop into sustainable operation because of the diversity of the stakeholders and their expectations.

Two major assessments explaining this lack of success are mentioned in the literature on organizational sciences, management, and economics. On the one hand, in many cases, the vision 
and ambition for the cluster are not sufficiently shared, built upon, included, or applied by the group of stakeholders (Kooli-Chaabane et al., 2008(a); Weil et al., 2010). On the other hand, the stakeholders have many difficulties cooperating, sharing value, and trusting one another, very often because they are competitors or because they do not know each other well or at all, for cultural and professional reasons (Calamel et al., 2011; D'amour and San Martin Rodriguez, 2006; Lartigue and Soulard, 2008). Thus, their thought processes and personal views of their respective organizations, objectives, wishes, fears, and reservations are not always understood and accepted by the others.

Consequently, to make an innovation cluster successful, it is necessary to create conditions conducive to the emergence of cooperation and trust among stakeholders, so that they feel understood, involved, and integrated in the design process of the action plan for the cluster, which is intended to enable the collaborative production and dissemination of new knowledge for innovation.

To address this issue, this article proposes a study of the application of the FAcT-Mirror method in the context of structuring an innovation cluster in the health care field, specifically pertaining to aging and autonomy, during the process of transformation from the emerging stage through the developing stage toward maturity. By enhancing the cooperative effort among representative stakeholders, this method makes it possible to go from a diagnostic phase to implementation of an action plan; the action plan is one that stems from the articulation of fears, attractions, and temptations that exist for each stakeholder of the system wishing to join the collaborative group (Le Cardinal et al., 1997).

This article presents a non-exhaustive review of the state of the art in the concept of an innovation cluster widely described in literature on organizational sciences, management, and economy, but also of the state of the art of characteristics of innovation clusters in aging and autonomy. It subsequently presents our problem statement and research hypotheses, along with the theoretical basis and the process of implementing the FAcT-Mirror method in application to our area of research. This article presents the conditions of application of the FAcT-Mirror method during the process of transformation from the emerging stage through the developing stage of the Sol'iage innovation cluster. This innovation cluster aims to support project owners (industrials, entrepreneurs, researchers, and health professionals) who wish to develop an innovative product and/or service to improve the quality of life of the elderly and their caregivers. Finally, it presents some formal results (shared definitions, three jointly proposed action plans) and informal results (commitments to carry out an action, common language, acquaintance with other stakeholders) collectively attained through a seminar and four work 
committee meetings that gathered 63 participants from fields of research, health, social sciences, and industry, representing 53 different public and private organizations.

\section{Review of the state of the art}

The innovation cluster is considered in this work to be "a system that, in an environment equipped with goals, practices an activity and sees its internal structure evolve over time, without losing, however, its unique identity" (Le Moigne, 1999). Whatever its form and nature, the innovation cluster is a particularly complex system because of the diversity of the stakeholders involved and the many interactions that bring them together in their multiple skills and areas of expertise. This diversity leads each of the stakeholders to view the cluster differently. According to Le Cardinal et al. (1997), "the three components of a complex system are the parts, the interactions, and the projects." The interactions may take place in four temporal spaces, each defining a type of complexity: during the discovery and construction of the identity (existential complexity), during the creation of relationships (relational complexity), during the conduct of operations (organizational complexity), and during the transfer of information (informational complexity) (Le Cardinal et al., 1997). Our study is concerned with the process that leads to the reinforcement of interactions between the stakeholders of an innovation cluster.

Thus, our review of the state of the art, which does not claim to be exhaustive, aims to place our research problem statement in the context of recent works found in the literature on organizational sciences, management, and economy that have treated the description and understanding of innovation clusters. Innovation clusters are often studied empirically after their creation (Hamdouch, 2008). These studies principally treat two lines of research. First, they are oriented toward conceptualization and modeling of cluster types. Second, they highlight factors that explain why the establishment of clusters fails or succeeds in certain contexts. They specify the policies, attributes, and stages of the life cycle of an innovation cluster. Our review of the state of the art therefore aims to understand these concepts and to respond to the following set of questions: Is there a universal definition of the concept of a cluster? What are the types and motivations of a cluster? Who are the stakeholders that comprise a cluster? Are there specific types of clusters? Are there attributes that are common to all types of clusters? What are the stages of the life cycle of a cluster?

\subsection{The cluster: economic, relational and territorial dimensions}

According to Porter (1998), "Clusters are geographic concentrations of interconnected companies and institutions in a particular field...,encompass an array of linked industries and 
other entities important to competition..., [and] are often extended downstream to channels and to customers and laterally to manufacturers of complementary products and to companies in industries related by skills, technologies, or common inputs." More recently, Rosenfeld (2002) defines clusters as "a spatially limited critical mass (that is, sufficient to attract specialized services, resources, and suppliers) of companies that have some type of systemic relationships to one another based on complementarities or similarities." This definition complements that of Porter, as the performance of a cluster also depends on its size in terms of number and density of stakeholders, in addition to the complementarity and similarity of its activities. Other studies explain the notion of this complementarity of activities by an affiliation with the same value chain (Cooke and Huggins, 2003). Finally, clusters may be defined following three axes: economic, relational, and regional (Lartigue and Soulard, 2008).

- According to the economic axis, the clusters consist of a grouping of companies and institutions from the same domain that are part of the same value chain and conduct complementary activities.

- According to the relational axis, links are formed between the units making up the cluster, and their actions are coordinated.

- Lastly, according to the regional axis, clusters are defined by their geographic expanse and their concentration in terms of number and density of stakeholders in the region concerned. According to Hamdouch (2008), "Despite numerous studies on the subject, neither the definition of what is actually a cluster (in general, and specifically in the case of innovation clusters), nor the demarcation of its spatial boundaries and its contents, nor even the identification of the conditions of its emergence and evolution are defined."

In view of the four aforementioned research works (Cooke and Huggins, 2003; Lartigue and Soulard, 2008; Porter, 1998; Rosenfeld, 2002), understanding the construction and evaluation of the interactions among the stakeholders seems to be particularly relevant when the cluster is looking to reinforce these interactions.

\subsection{Innovation clusters and French policies}

For more than 10 years, the French state and administrative regions have pursued economic development policies that stimulate all forms of innovation (Boly et al., 2000; Boly, 2008; Gaffard, 2004; Garcia and Calantone, 2002) and encourage strategic market alliances of the economic stakeholders of a region (OECD, 2005). These "cluster" policies aim to create ecosystems that are conducive to innovation (they disseminate and create new knowledge) and to promoting the emergence of collaborative organizations that may take a variety of forms (local 
production system, competitive cluster, industrial district, center of expertise) according to the needs of different markets and strategic regions (Cooke and Huggins, 2003; Lartigue and Soulard, 2008, Porter, 1998). Each triennial period, the French state allocates 1.5 million euros for the development and organization of the 71 competitive clusters (Fontagne et al., 2010).

According to Forest (2009), competitive clusters bring a variety of stakeholders in a given geographical area and in a complex relational system together on a single productive theme.

These clusters materialize the idea that connecting innovation stakeholders can stimulate the dissemination of knowledge necessary for innovation.

They support the innovative capacity of firms, which has become a major point of focus in public policies of developed countries (Boshma and Ter, 2009).

Competitive clusters are intended to gather a variety of stakeholders (research labs, large companies and small and medium enterprises, both industrial and service) that are in a complex relational system on a common point of knowledge. Despite some cases of success, the collective dynamics of such competitive clusters is often questionable and inefficient.

According to Forest (2009), the innovation cluster in France is a tool to disseminate innovation policies in specific markets of knowledge, and it should also fulfill two main functions: (1) to disseminate the necessary innovation knowledge among all of the market stakeholders and (2) to enable these stakeholders to create new knowledge together.

Nevertheless, analysis of policies supporting innovation cluster development in France (policies on local production systems in 1998, competitive clusters in 2002, and industrial districts in 2009) shows that many clusters have not sufficiently responded to their motivations, missions, or value creation objectives. Even if there are many studies that define the types, motivations, attributes, stakeholders, and life cycle stages of a cluster, there are few studies that focus on understanding the mechanisms that guide and structure cluster objectives, values, actions, and ambitions efficiently and collaboratively (Lartigue and Soulard, 2008). According to Hamdouch (2008), "today the actual stakes lie in the understanding of the processes leading to the creation of clusters and networks, and of their forms of structuring and evolution, mainly in domains where relationships between [stakeholders] prove to be decisive for innovation."

2.3. A specific type of cluster: the innovation cluster in health care that pertains to aging and autonomy 
A specific type of innovation cluster, that in health care pertaining to aging and autonomy, is emerging in France (Zimmer, 2012) and internationally (Lendel, 2006). Among clusters of this type in France are the "Autonom lab" center of expertise, founded in 2008 in the Limousin region of France, the Alps Technology Cluster Association for Home Health and Autonomy (TASDA, from the French l'Association Technopole Alpes Santé à Domicile et Autonomie) created in 2009 in the Rhône-Alpes region, the Madopa ${ }^{3}$ association created in 2010 in the Champagne-Ardenne region, the Health Center of Expertise created in 2004 in Sherbrooke (Canada), and the Sol'iage innovation cluster created in 2011 in the Île-de-France region. This type of cluster is particularly complicated to induce into emergence and develop into sustainable operation, because of the diversity of the stakeholders and of their expectations. A key element in this new type of cluster is the users and/or their representatives.

These new stakeholders intervene at different milestones of the development of innovative products and/or services (execution of tests/validations, validation of user requirement specifications, and validation and articulation of needs that might be addressed in an ideal case, in order to set a goal to strive for in development). This type of cluster is characterized by:

- Complexity of the market and interactions among its stakeholders, who come from medical, scientific, economic, entrepreneurial, industrial, and home health care sectors and do not know each other well or at all, for historical or cultural reasons. These interactions are without equivalent; they take place so that an innovative idea can be translated into the launch of a product or service or even the creation of a successful business;

- Co-creation of value (economic, scientific, health care, and home health care) by its stakeholders;

- Low level of maturity in the industrial domain of technologies for health and autonomy (Gimbert, 2009);

- Significant and sometimes opposing diversity in the expectations and views of the cluster by stakeholders who do not share the same value creation interests during the emerging stage of the cluster;

- Lack of human potential and financial resources to bring the cluster to life;

\footnotetext{
${ }^{2}$ www.limousinliviglab.fr

${ }^{3}$ www.madopa.fr
} 
- Low capacity of the decision-makers to make choices and move from intent to action;

- Empathy of the stakeholders toward the final users (of the products and/or services), as stakeholders are often committed personally because of their individual and family experiences and have sometimes committed their businesses as well;

- A fairly heterogeneous culture, in terms of tools and methods, for implementing a collaborative structure and balanced management;

- Motivation that aims to offer project owners an ecosystem favorable to innovation, by making collaborative project engineering skills, tools, and methodologies available to them;

- A strategy for co-design of multidisciplinary and fair governance, despite significant professional corporatism.

In the health care sector, on-site tests and validations of the innovative product and/or service are very important, costly, and non-standardized.

\subsection{The attributes of an innovation cluster}

Clusters of every type have more or less similar attributes, or characteristics, that allow them to differentiate themselves from one another. When we examine the network in its management of technological skills, the characteristics that are desired for a network are a horizontal vision, sharing of costs and risks, collective learning, creation of experiential knowledge and skills, and an active collective resulting from technological complementarities, non-commercial interdependencies, and a flow of information (Guilhon and Gianfaldoni, 1990).

Table 1: Attributes of a "network of competence" cluster, according to Bejean and Gaudreau, 1997; Cooke and Huggins, 2003; Lartigues and Soulard, 2008; Porter 1998; and Ritter and Gemunden, 2003

\begin{tabular}{|c|c|}
\hline Attribute & Example \\
\hline 1. Joint vision among stakeholders & $\begin{array}{l}\text { Strategy, risk, objective, mission, activity, } \\
\text { and process }\end{array}$ \\
\hline 2. Resource sharing & Material and human \\
\hline $\begin{array}{l}\text { 3. Complementarity of competence } \\
\text { and knowledge in a market }\end{array}$ & Consumer, suppliers \\
\hline 4. Sharing of informal and formal & Seminar, e-mail communications \\
\hline
\end{tabular}


information

5. Cooperative work habits

6. Support of innovation in response to a challenge

7. Governance

8. Geographic anchoring

9. Geographic visibility

10. Stakeholder investment

11. Identity

12. Values
Cooperative tools (virtual platform)

Innovative idea detection process

Rules, regulations, stakeholders

Regional

Local, national, and/or international

Presence in meetings, dues

Cluster history

Economic, health, ethical

Other authors define network characteristics taking from both the theory and the reality of clusters (Lartigue and Soulard, 2002). For instance, according to Lartigue and Soulard (2002), the network characteristics are: thematic focalization, regional concentration and anchoring, organization and identity of the network, stakeholders intervening at different levels of value creation, collaborative innovation methods, durability of the network, capacity for innovation, and value creation potential. Network characteristics can also be regarded from the perspective of the motivations behind the network (Bejean and Gaudreau, 1997). According to Bejean and Gaudreau (1997), the desired features of a network, especially one in health care, are characterized by a collective behavior that is adequate for its objectives, affinity in relationships (formal or informal), complementarities between knowledge and skills, synergies, efficiency, and a development of knowledge and skills. Finally, the characteristics of a network can be described according to the capacity of a stakeholder to manage his or her network to make it robust and fruitful. According to Ritter and Gemunden (2003), the characteristics of good network management are: access to different network resources (physical, personal, financial, informational), circulation of information through formal (work groups, seminars) and informal (daily collaborations) conduits, and technological intermingling (incorporation of the members of the network in the conception and generation of ideas and products) (Ritter and Gemunden, 2003). In Table 1, we propose a grouping of twelve attributes to generically characterize clusters of every type, according to the four aforementioned work groups. 
Table 1 presents twelve attributes that we can consider, integrate, describe, construct, and evaluate in the process of transformation of an innovation cluster in the home health care sector from an emerging stage through a developing stage toward one of maturity. This synthesis demonstrates the importance of having a method available that allows efficient guidance and monitoring of the creation of these attributes. Our topic of research is located precisely at this level; that is, to understand the underlying mechanisms that it will be necessary to integrate and consider as best practices in the development of a cluster. Is the emergence of these attributes in a cluster correlated to its stage of maturity in its life cycle?

\subsection{The life cycle of a cluster}

According to Clunet (2008), the life cycle of a cluster consists of five chronological stages, whatever its type, motivation, or regional anchoring (see Figure 1).

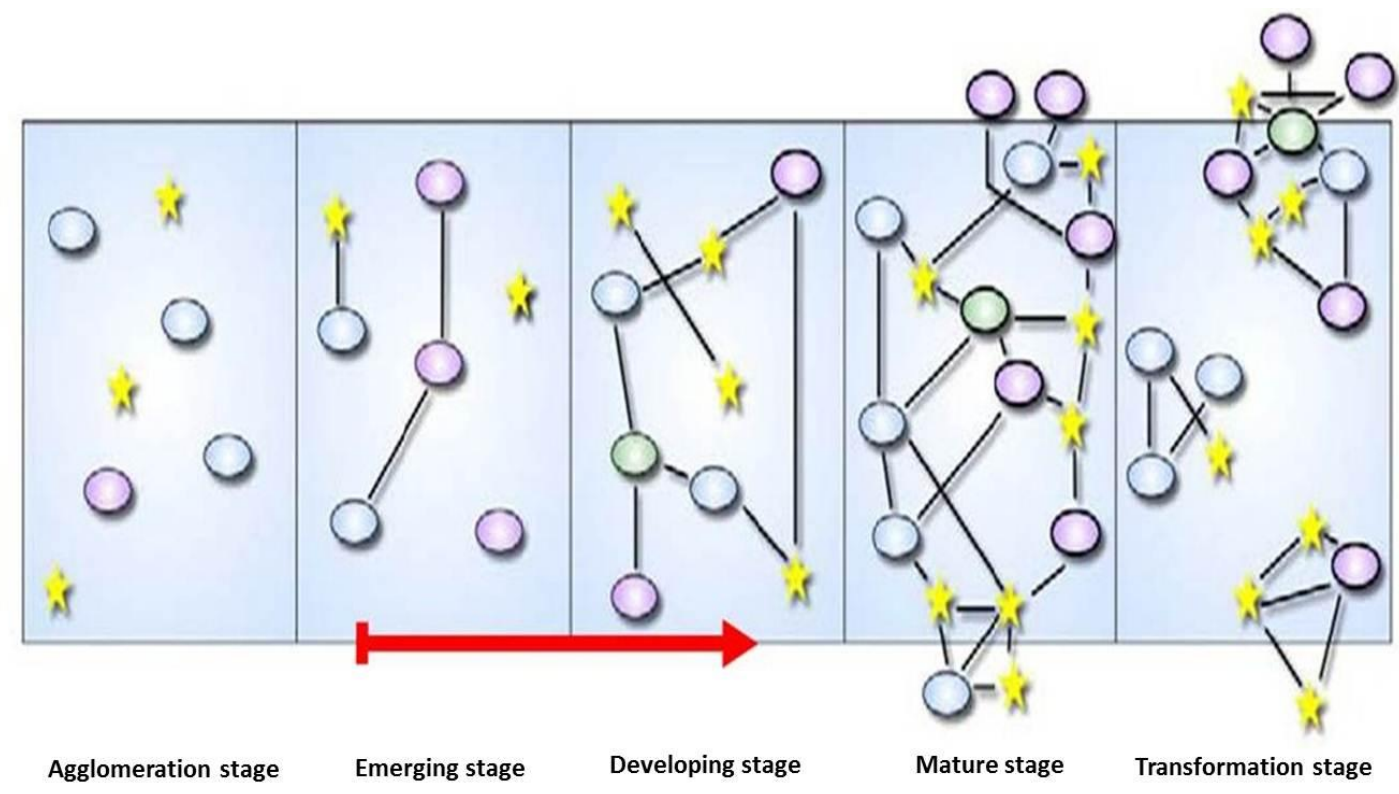

Fig. 1: Cluster life cycle stages (Clunet, 2008) and situation of SOL'IAGE innovation cluster (red arrow)

These five stages are:

- “Agglomeration stage: A region has a number of companies and other [stakeholders].

- Emerging stage: As an embryo to the cluster a number of the [stakeholders] in the agglomeration start to cooperate around a core activity, and realize common opportunities through their linkage. 
- Developing stage: As new [stakeholders] in the same or related activities emerge or are attracted to the region, new linkages develop between all these [stakeholders]. Formal or informal IFCs, [Institutions for Collaboration], may enter the field. Often a label, website, common connotation, tied to the region and activity, starts to appear.

- Mature stage: A mature cluster has reached a certain critical mass of [stakeholders]. It has also developed relations outside of the cluster, to other clusters, activities, regions. There is an internal dynamic of new firm creation through startups, joint ventures, spinoffs.

- Transformation stage: As time goes by, markets, technologies, and processes change, as do clusters. In order for a cluster to survive, be sustainable and avoid stagnation and decay, it has to innovate and adapt to these changes. This can take the form of transformation into one or several new clusters that focus around other activities or simply a change in the ways that products and services are delivered."

Finally, we note from this presentation of the state of the art that literature describing and analyzing existing clusters and their level of maturity is abundant (Clunet, 2008; OECD, 2001; Rosenfeld, 2002). Nevertheless, this research is currently still empirical because of recent cluster policy, particularly in France (Fontagne et al., 2010). According to our understanding, there are studies that examine the performance of clusters by evaluating them with dashboard indicators for cluster characterization and impact (Clunet, 2008). These studies are still done when the clusters are mature (established governance, regional anchoring, defined objectives, etc.). Other studies investigate the process of data transfer with intermediate transfer tools used among stakeholders who already work together in an organization that is already established, in order to control the quality of this transfer and the circulation of data (Kooli-Chaabane et al., 2008(b), 2010). However, few studies focus on understanding the process of transformation from the emerging stage toward maturity of the interactions among the different stakeholders of a cluster, and more specifically, an innovation cluster in the health care domain pertaining to aging and autonomy.

According to Hamdouch (2008), "knowledge of the practical mechanisms used in the dynamics of emergence, structuring, coordination and development of the phenomena of agglomeration of productive activities and of innovation are partial, scattered and not very robust." Furthermore, according to the same author, it seems that "the focus is now put on the way that public and private [stakeholders] of very different natures (industrial and service companies, research centers, universities, funding agencies, public authorities and agencies) interact and coordinate 
to promote the development of dynamic, viable local or regional spaces in specific industrial, scientific and technological domains."

\subsection{Research problem statement}

It may be relevant to use an existing methodology to understand and measure the performance of the process of transformation between each stage in the life cycle of a health care innovation cluster at the moment when the stakeholders move from a state of intention to one of action. This work could be particularly useful for this type of cluster, which is particularly complicated to induce into emergence and develop into sustainable operation, because of the ignorance and diversity of the expectations of the stakeholders.

The question is how to create favorable conditions for the emergence of cooperation and trust among stakeholders, so that they feel understood, involved, and integrated in the design process of the cluster action plan, which is intended to enable dissemination and collaborative production of new knowledge for innovation.

\subsection{Research Hypotheses}

We base the present research on four hypotheses:

- The structuring of an innovation cluster is efficient if the creation of a shared and global vision of the objectives, risks, and ethical rules is established by the group of stakeholders and guided by an original method of complex problem solving;

- The structuring of an innovation cluster is efficient if all of the stakeholders in the cluster have collectively designed, detailed, and validated conditions of success and project implementation action plans, using a methodology;

- The structuring of an innovation cluster is efficient if collaborative work habits among the stakeholders, as well as common definitions and tools, are constructed and assimilated by the stakeholders as a group;

- The direction and monitoring of the implementation of the actions of a cluster, at whatever stage of maturity in its life cycle, is effective if a tool and/or methodology permits an evaluation of actions that have already been implemented. Here, the objective is to form a collective definition of best practices in order to avoid possible sources of conflict among the stakeholders of the cluster, and to simulate the impact of actions implemented to perpetuate the system. 
To validate these research hypotheses, we have selected the FAcT-Mirror method.

\section{Methodology}

\subsection{Theoretical basis for the FAcT-Mirror method}

This method, used in a collaboration of representative stakeholders, has made it possible to move from a diagnostic stage to a stage of development of a collective action plan that is based on an articulation of fears, attractions, and temptations. This process occurs among the stakeholders of the system who wish to join the collaborative organization. The following section presents the FAcT-Mirror method, which seems particularly suitable and effective among other methods in making such robust and fruitful collaborations. It has never been applied to an innovation cluster in the home health care domain, more specifically at the transformation point of the process, where the cluster moves from a state of intention to a state of action realization.

This preventive work enables interaction between the stakeholders who are not accustomed to working together and articulation of the set of indisputable commonalities that they all share. For this reason, the exercise is particularly recommendable for use during the period of transition from an intention to do to a will to act for all types of clusters. The exercise could make it possible to evaluate the feasibility of establishing a cluster in a region, and avoid unnecessary expenditures. It could allow value to drive the performance of a collaborative organization, like the method of direction of a complex system by values (Schindler et al., 2007). This method is particularly suitable for collaborative organizations where the number of stakeholders is significant and where their acquaintance with one another is very slight.

Figure 2 shows that the FAcT-Mirror methodology makes it possible to simultaneously execute three types of management: risk management, goal management, and ethics management (Le Cardinal et al., 1997). These three types of management are constructed from interactions that are provoked by the necessity of cooperation for the resolution of a complex problem. This construction of common views of the complex system and of its actions takes place both collectively (articulation of fears, attractions, and temptations; determination of unavoidable themes; definition of dangers, goals, and values; development of lines of action; and definition of precautions, means, strategies, and best practices guidelines) and individually (evaluation of fears, attractions, and temptations) for each of the stakeholders. The objective of the application of the FAcT-Mirror methodology is to reduce the fears, increase the attractions, and neutralize the temptations that the stakeholders might have with respect to one another or themselves. This exercise is carried out to construct both a joint representation of themes and sub-themes and an action plan structured by lines of action, detailed, shared, and validated by everyone. The 
methodology makes it possible to establish a dynamic process of cooperation in which the stakeholders commit, in the presence of the others, to carrying out the recommended actions that concern each of them individually.

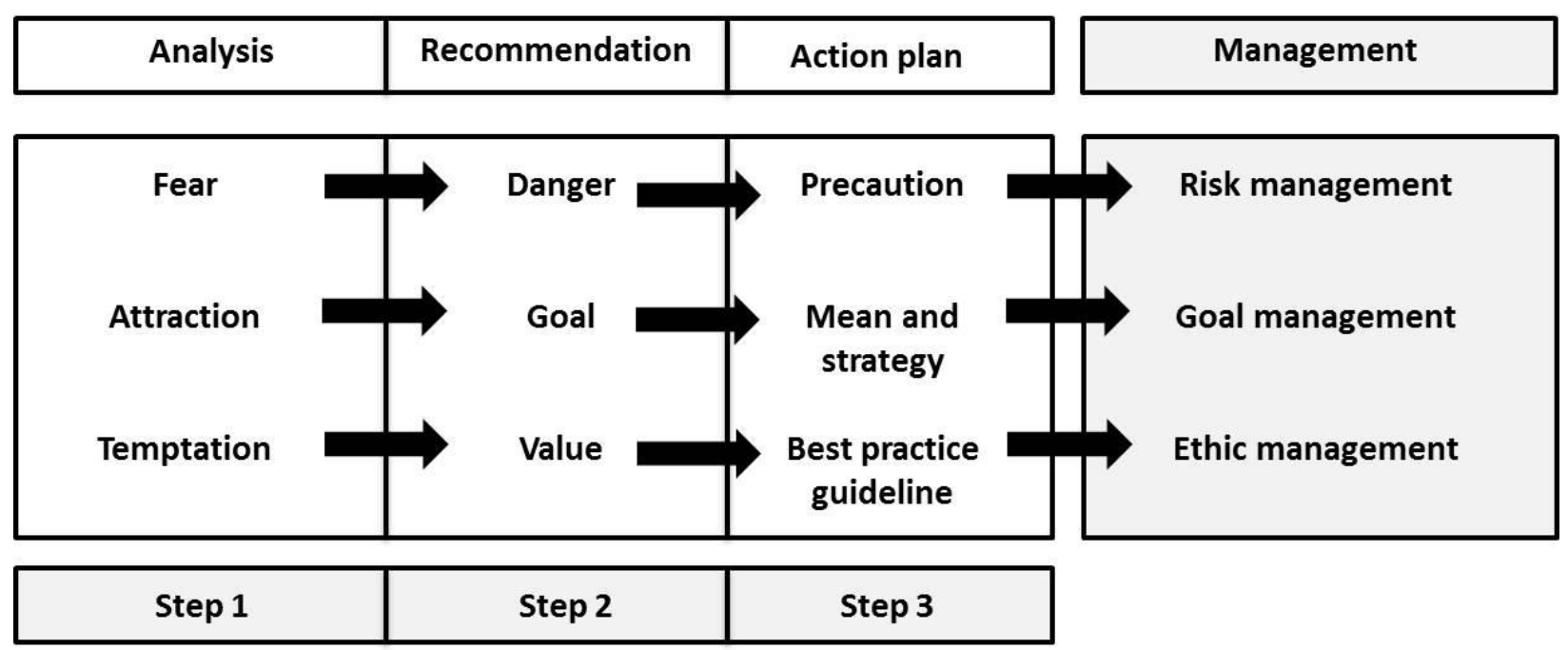

Fig. 2: FAcT-Mirror methodology: The action implementation process leads to three types of management

\subsection{Interpretation of results}

The FAcT-Mirror method makes it possible to represent all of the interactions generated (fears, attractions, and temptations) between each pair of stakeholders as a map. It helps to illustrate and identify the intensity (I) of these interactions and to reveal the schemes of cooperation that may turn into potential sources of conflict between two stakeholders. This intensity corresponds to the sum of fears $(\mathrm{F})$, attractions (Ac), and temptations $(\mathrm{T})$.

$\mathrm{I}=\sum(\mathrm{F}+\mathrm{Ac}+\mathrm{T})$

This indicator, facilitated by the availability of the FAcT-Mirror software, allows for a better appreciation of the collective representation of the cluster and the complex problem. Those who participate in the activity "Collect data" can appreciate the schemes of cooperation involved in the complex problem in real conditions (Le Cardinal et al., 2001). This valuable moment allows them to converse, reexamine themselves, and collectively confront their view of the situation in order to construct a joint vision together. It aids in anticipating existing problems or problems that could arise and in putting actions that aim to reduce fears, increase attractions, and stabilize temptations into place. According to Le Cardinal et al. (1997), there are six types of possible 
schemes of cooperation that the FAcT-Mirror moderator can expect to see during analysis of results obtained from the interactions between stakeholders of a system (see Figure 3 ).

Figure 3 presents the six possible schemes of cooperation. This exercise can be done at all stages of the life cycle of a complex system.

For each of the six possible schemes of cooperation, a good analysis of these schemes consists in:

- Evaluating the intensity (I) of the interactions between two stakeholders;

- Evaluating the danger (D), which corresponds to the sum of fears (F) and temptations (T), elements that are detrimental to cooperation: $\mathrm{D}=\mathrm{F}+\mathrm{T}$;

- Evaluating the polarity $(\mathrm{P})$, which corresponds to the difference between fears and temptations: $\mathrm{P}=\mathrm{F}-\mathrm{T}$.
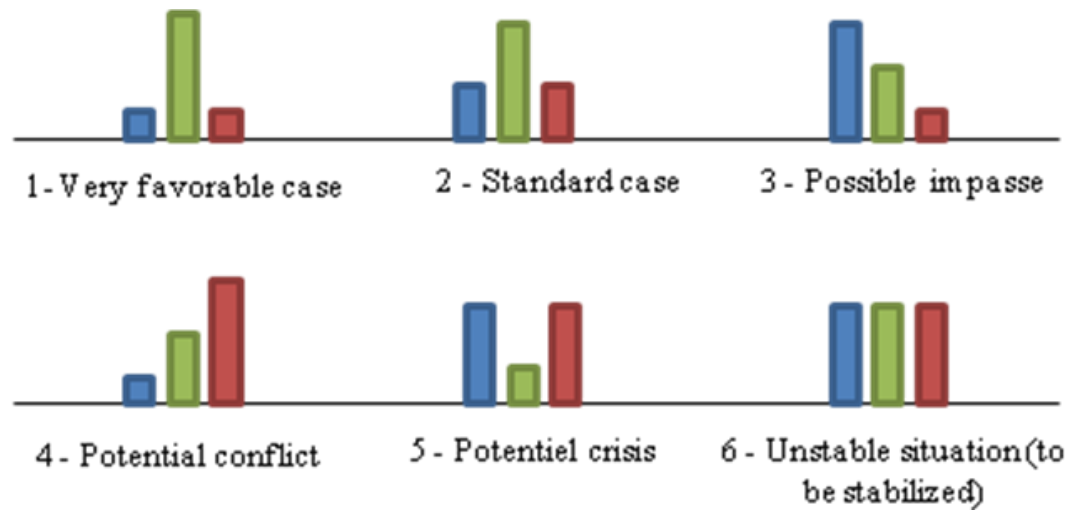

Fig. 3: Classification of the six possible schemes of cooperation between stakeholders in a complex system (Le Cardinal et al., 1997). (In each histogram: fears are in the leftmost, blue column, attractions are in the center, green column, temptations are in the rightmost, red column.)

A scheme of conflict between two stakeholders is always characterized by a negative polarity. In the six possible cooperation schemes, this corresponds to the "potential conflict" and "possible conflict" schemes (see Figure 3). These cooperation schemes are the most dangerous for the collaborative structure.

\subsection{Presentation of case study: Sol'iage innovation cluster}

In France, innovation in gerontechnology is essentially the work of individual project owners. These project owners come mainly from the health care and research industries. The motivations 
and values that they bring to idea generation, project development, and product sales are different according to the professional domain to which they belong. Due to his or her professional background, the project owner very often does not have all of the necessary skills for the project and must therefore rely on an innovation cluster of external experts for such actions as realizing testing and validations, defining the level of patentability of the concept, defining user requirement specifications, measuring the work of the project owner against that of the competition, articulating needs that might be addressed in an ideal case (thus setting a goal to strive for in development), and being aware of the mechanisms of petty reimbursement systems in order to define one or more economic model scenarios, etc. The project owner in this context requires medical, technical, commercial, financial, and managerial skills.. The Sol'iage innovation cluster was created in order to respond to the many expectations of project owners, expectations that were detected and articulated through a Charles Foix research and innovation grant (the Bourse Charles Foix), for which more than 100 innovative project application submissions have been evaluated since 2004. Some stakeholders had a shared vision to create an ecosystem that is favorable to innovation in products and/or services meant to improve the quality of life of the pair comprising the caregiver and the elderly person in the process of losing his or her autonomy. It is a participatory response to the inadequacy between the supply and demand in gerontechnology. The Sol'iage innovation cluster is characterized by its history and its regional anchoring (to the Ile de France region of France) in structuring an evolving competitive market, with all of the stakeholders in the health and autonomy value chain united around a strong and incorporative trait: taking into account the betterment of (societal) human life. This innovation cluster in the health care sector is particularly complicated to induce into emergence and develop into sustainable operation because of the diversity of its 35 constituent members: venture capitalists, public innovation support organizations, a health professionals association, a patients association, an intellectual property protection consultant, a marketing consultant, researchers in the social and hard sciences, and insurance organization representatives (Zimmer, 2012).

Despite real intentions to cooperate, the actions of this cluster are slow to develop, because the stakeholders do not feel sufficiently involved and engaged. Their interests (ambition, resources, and values) in the cluster are different, as are their familiarity with and expertise in the market.

\subsection{Selection and roles of the participants}

Potential participants were chosen by the cluster project head from the Sol'iage innovation cluster contact directory, containing over 850 French and international contacts in gerontechnology markets. This list was then proposed and validated by the steering committee of 
the innovation cluster, consisting of 12 members from the health care, research, and industry domains (Zimmer, 2012).

Approximately one hundred prospective participants were approached following an email explaining the testing conditions and its utility in the identification, planning, and structuring of the actions of this type of cluster. Finally, they were recruited following the reception of an email indicating their approval. The return rate was over $60 \%$. Some were unable to attend this event and regretted their absence, which was due to other constraints; these individuals expressed their interest in the results of this methodological exercise.

During two brainstorming sessions, four work committee meetings, and two steering committee meetings that were organized between May and September 2010, the following groups were represented as participants in these events: users, user representatives, researchers, manufacturers, certifiers, distributors, project owners, municipalities, public administrations, health professionals, funders of autonomy, designers, industrials, innovation support organizations, and insurance organizations. Participants were able to play, in turns and as a function of work time, the role of a stakeholder during a brainstorming session and the role of an evaluator/decision-maker during a steering committee meeting.

The deployment of this method allowed us to bring together 63 individuals representing 53 different institutions involved in or pertaining to specific milestones of the value chain in the design of an innovative product and/or service and of the chain of experiences between clients and users in the field of gerontechnology (see Figure 4).

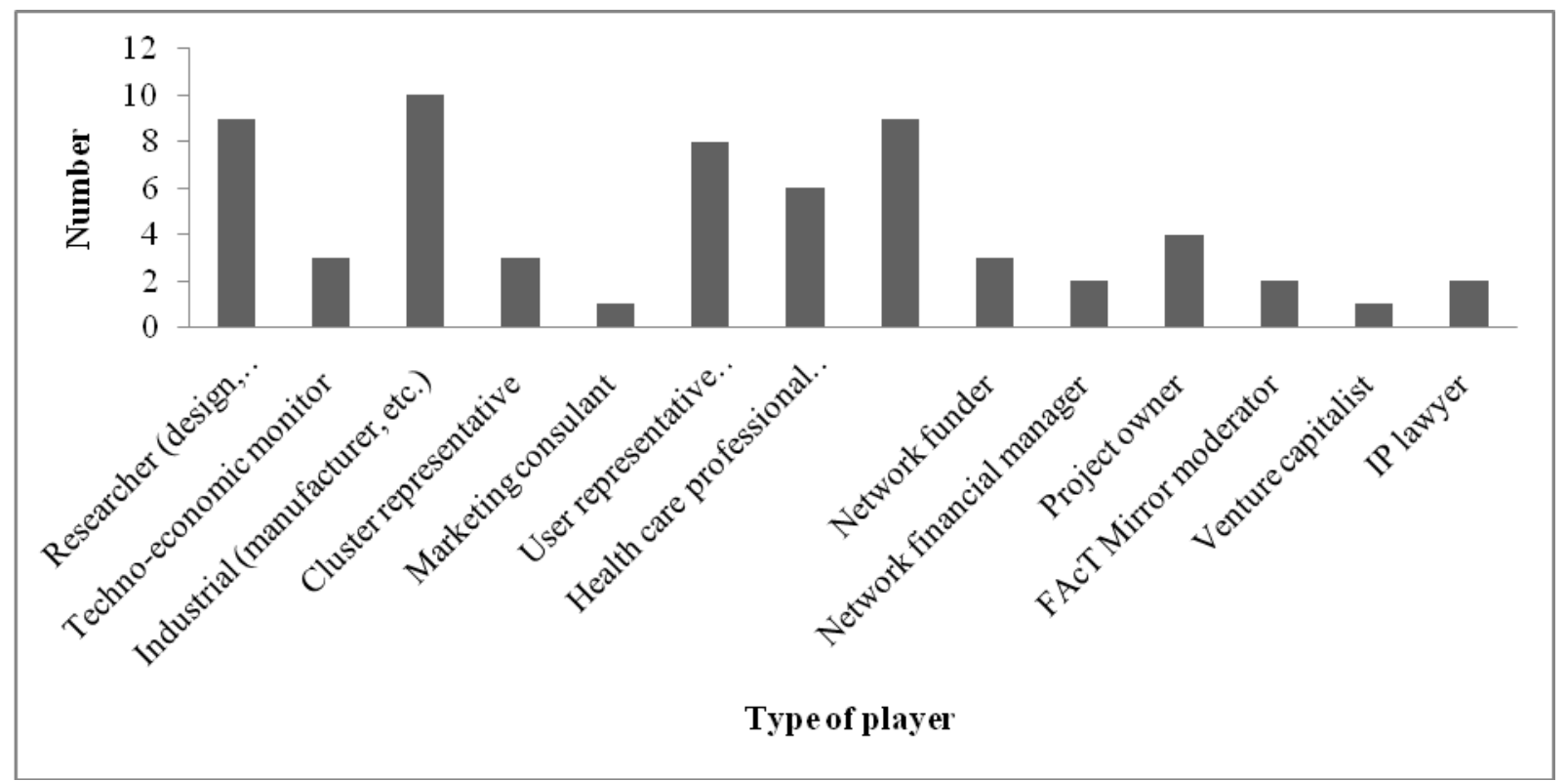


Fig. 4: Histogram presenting the classification and number of participants

Figure 4 shows that the significant number and the diversity of the stakeholders who participated in this exercise of devising actions enabled us to have representative samples of the global views of the stakeholders involved in this market.

\section{Results and Discussion}

We present a few of the principal results of the application of this methodology and discuss their utility in the context of its application to innovation clusters, especially to innovation clusters in the health care sector pertaining to aging and autonomy, when the decision is made to reinforce the interactions between stakeholders. These results are presented using the FAcT-Mirror methodology described in Figure 2.

\subsection{Jointly proposed definition of aims}

The aim of the Sol'iage innovation cluster, validated by the participants in the FAcT-Mirror seminar, is: "to stimulate the inception and support the formation, validation, and dissemination of innovative, ethical, and environmentally responsible solutions (technological, methodological, and human) suitable for patients and their personal and professional circles, based on the acquaintance with and anticipation of their needs by bringing the multidisciplinary skills and the experiences of the members of the cluster together." This aim could be applied to all innovation clusters in home health care that pertain to aging and autonomy.

\subsection{Jointly proposed typology and definitions of the stakeholders}

The participants subsequently took 30 minutes and proposed a grouping of gerontechnology market stakeholders into four broader classes of stakeholders, which they defined (Table 2).

Table 2: Glossary presenting the cluster stakeholders associated with four broader classes of stakeholders

\begin{tabular}{llc}
\hline $\begin{array}{l}\text { Class of } \\
\text { stakeholder }\end{array}$ & Type of stakeholder & Definition \\
\hline
\end{tabular}

User User representatives, users, health professionals
Elderly person in the process of losing autonomy, health professional, or juristic or natural person who represents and knows the needs of the elderly person and who directly or indirectly uses an innovative product and/or service to improve his or her quality of life and/or work conditions 
Project Entrepreneur, scientist, owner industrial, health professional

Project owner service provider

Cluster service provider monitor, marketing consultant, cluster representative, innovation support structure representative, venture capitalist, prescribing practitioner, funder, industrial (manufacturer, supplier, distributor)

Cluster representative, cluster funder, cluster financial manager
Natural person from the industrial, health, or research field who supports an idea and who may or may not wish to develop an innovative product and/or service. The motivations and values that lead him or her to produce an idea, develop a project, and sell a product vary according to the professional setting to which he or she belongs. This diversity is characterized by his or her level of investment (personal and financial), resources (skills), understanding of needs and of the health care system (stakeholders), ability to define an action plan (innovation management), and difficulty in evaluating the risks and required skills in an $\mathrm{R} \& \mathrm{D}$ project.

Natural person, cluster member, who sells a service to a project owner during the development stage of a product or service in gerontechnology.
Natural person, cluster partner, who contributes to structuring the cluster by allotting human, financial and material resources.

This typology could be used for all types of innovation clusters in the domain of health care pertaining to aging and autonomy. This work would aim to ensure that all of the stakeholders in these types of complex systems are defined and that they might be more easily involved, convinced, and integrated into the transformation process. We note that it is based on this work that we will study the interactions between these four types of stakeholders.

\subsection{Jointly proposed map of interactions and schemes of cooperation between each stakeholder}

The map of the classification of interactions (see Figure 5) between the stakeholders of the Sol'iage innovation cluster during its process of transformation from the emerging stage through its development shows that two schemes of cooperation appear out of the six possible schemes (see Figure 3): "standard case" (3) and "possible impasse" (8) (see Figure 5). This exercise made it possible to gather 1002 fears, attractions, and temptations [390 fears (blue items), 387 attractions (green items), and 225 temptations (red items)] (see Figure 5). Figure 5 illustrates the result of the first step of the production process of an action plan proposed by the FAcT Mirror method (see Figure 2). 
Zimmer B., Le Cardinal J., Yannou B., Piette F., Baly V., Le Cardinal G. (2014) 'A methadalogy far the development of innavation clusters: Application in the health care sector', International Journal of Technology Management, vol. 66, по. I, pp. 57-78, doi: 10.1504/|JTM.2014.064017

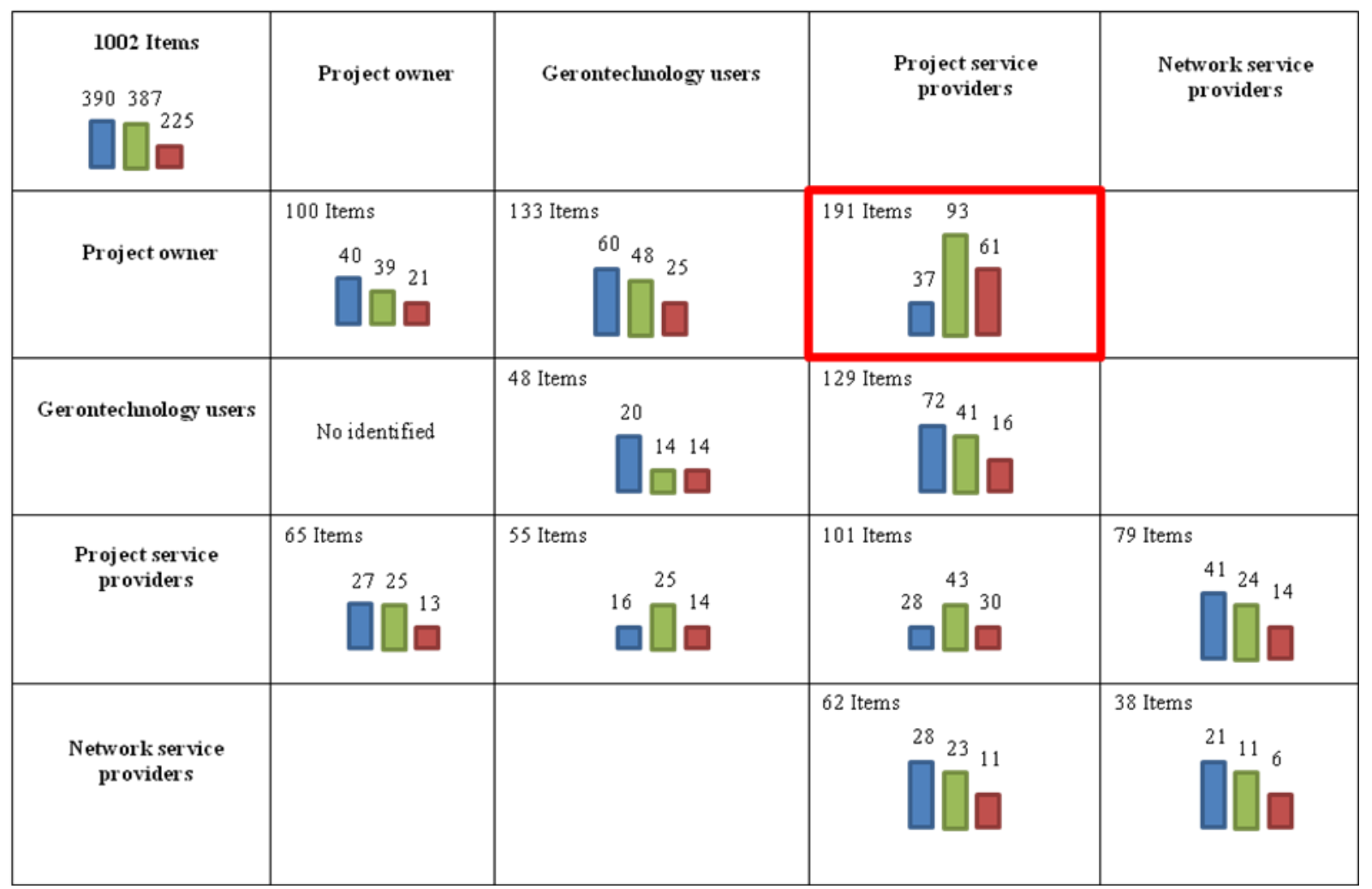

Fig.5: Map of interactions between stakeholders of the cluster

Figure 5 shows that the most significant intensity exists between the project owner and the project service providers. The result may be explained by the fact that the project owner needs to establish value and concept proofs to assess whether or not their new product or service development is adapted to a market. To do so, the project owner needs the project service providers, who might not take his comments into account in evaluating the benefits of an innovative solution.

We also note that the two types of impasse schemes, which correspond to a number of fears greater than or equal to the number of attractions and/or temptations, stem from three types of interactions, those between:

- the project owner service providers and the cluster service providers;

- the cluster service providers and themselves;

- the gerontechnology users and the project owner service providers. 
In conclusion, this dynamic exercise made it possible to illustrate and collectively anticipate future complex problems with which the cluster could be confronted if it were to not employ the necessary means and to not take preventive measures that aim to reduce dangers, increase attractions, and neutralize temptations. One of the indirect effects of this exercise is both to acquire a joint vision for the establishment of a sustainable collaborative structure, and to engage each stakeholder in realizing this vision. It is of particular interest to repeat this analytical exercise when the interactions have been classed into unavoidable themes. This exercise shows the unavoidable themes that need to be addressed urgently.

This result is especially relevant in view of the analysis of failures described in the literature on clusters (Hamdouch, 2008; Lartigue and Soulard, 2008). This complex problem solving method is of particular interest in meticulously evaluating potential sources of conflict that the organization will have to face or counter, while establishing avoidance strategies developed by the group of stakeholders in the system studied. In our study, we place ourselves upstream of this analysis, in the dynamic of the process of transformation from an emerging, or intention, stage, through that of development, or action, in order to understand the mechanisms and processes to be implemented to devise a type of cluster with an efficient organizational structure. This work has helped to converge the different views of the stakeholders of the innovation cluster into a joint vision of the cluster.

\subsection{Jointly proposed grouping of the data and production of recommendations}

The second step of the FAcT Mirror method (see Figure 2) creates the necessary recommendations to limit fears, increase attractions and avoid temptations. In order to produce these recommendations, four work committees are created. Each work committee is defined and includes participants who are divided according to their skills and their level of involvement and availability for structuring the cluster (Table 3).

Table 3: Definition of cluster work committees

Nature of
committee

User committee
The main objective of the "user" committee, a committee in parallel with the three others, is to monitor the ethics of the work being done and to validate the documents, taking into account the wish to contribute to a longer improved quality of life for the caregiver and elderly person. 
Cluster commitee

Project committee

Resource committee
The main objective of the "cluster" committee is to offer improvements to the current, established governing structure and to define the strategy, means, and resources to be implemented in order to attain the ambition of the innovation cluster.

The main objective of the "project" committee is to define the project owner support process (best practices, conditions for success) and the trainings to develop in response to their expectations and needs.

The main objective of the "resource" committee is to define the framework documents that will make it possible to contract best practices as well as the relationships between the stakeholders of the innovation cluster.

This collective formation of the committees allows each participant to understand and discuss the nature of the management of the work. It is a horizontal, rather than vertical, management, incorporating the assorted perspectives and involving all of the stakeholders. This logic of formation can be applied to all types of clusters, in particular to industrial sectors whose level of maturity is relatively low and in which the stakeholders know each other little or not at all, as their skills and interests in the structure are different. This management of the work might make it possible to harmonize the equitable sharing of value among the stakeholders in a cluster, whatever the nature of the value. This type of management is a joint construct that involves the stakeholders to a greater extent than work carried out in its absence.

The participants created action plans in the four work committee meetings based on precautions, means, and guidelines that were established based on the fears, attractions, and temptations generated at the FAcT-Mirror seminar (see Figure 2). They met for a half-day of work to identify the recommendations that the cluster should apply at the moment of execution of these actions. These four work committees defined 345 recommendations. They subsequently defined the lines of action, then the sub-lines of action, and then the actions. Finally, three action plans were devised by grouping the lines of action by their affinity. This grouping task was suggested by moderators certified in the FAcT-Mirror method and then validated by the cluster steering committee.

Each defined action specifies: Who realizes the action? What is expected of this action? In what conditions is this action executed (where)? How is this action executed? What are the financial, informational, and human resources that the cluster can make available? The role of the steering committee will also be to define the resources, projected calendar, and level of priority of the implementation of these actions (very short term, short term, medium term, long term). 


\subsection{Three jointly proposed action plans for an innovation cluster}

The application of the FAcT-Mirror exercise in the context of the Sol'iage innovation cluster during its transformation process generated three action plans, entitled "Governance and Strategy," "Tools and Contracts," and "Project Owner Support and Training." These action plans are to be implemented in this complex organization in order to meet the collective needs of the stakeholders involved in the design of an innovative product and/or service in gerontechnology and in order for the structure to be sustainable. Table 4 presents "Action Plan 1: Governance and Strategy," produced by the FAcT Mirror method (see Figure 2). It is an example that is based on two main lines of action: "Draw up and implement a governing structure for the cluster" and "Manage the image and human, scientific, and technical potential of the cluster." Each of these lines of action consists of sub-lines of action where the precautions, means, and best practices guidelines are formulated based on dangers, goals, and values defined in the innovation cluster diagnostic phase. One of the actions in this plan is to develop a governing structure based on the recommendations collectively developed by the stakeholders.

Table 4: Presentation of lines of action of Action Plan \# 1 of Charles Foix health care innovation cluster

\section{Action Plan 1: Governance and Strategy}

\section{Line of action 1.1. : Draw up and implement a governing structure for the cluster}

sub-line of action 1.1.1.: Structure the governance of the cluster

sub-line of action 1.1.2.: Define a strategy for the cluster

sub-line of action 1.1.3.: Seek financing and manage financial resources

sub-line of action 1.1.4.: Draw up code of ethics for the cluster

sub-line of action 1.1.5.: Participate in conferences held by national organizations dealing with gerontechnology

\section{Line of action 1.2. : Manage the image and human, scientific, and technical potential of the cluster}

sub-line of action 1.2.1.: Manage the human potential of the cluster

sub-line of action 1.2.2.: Promote encounters between the stakeholders of the cluster

sub-line of action 1.2.3.: Build cluster image and communicate it externally 
As mentioned by several authors in the literature (Hamdouch, 2008 ; Lartigue and Soulard, 2008; Weil et al., 2010), many clusters do not attain the objectives sought because the stakeholders do not all have a global, structured, structuring, and shared vision of the action plans. For an innovation cluster in health care, the three action plans could be used as a best practices guide to efficiently direct the transition, in function of available human, financial, and material resources, from the emerging stage through the developing stage toward maturity.

\section{Outlook and conclusion}

The application of the FAcT-Mirror method to the Sol'iage innovation cluster, during its reinforcement phase, mobilized 63 participants from 53 different professional bodies for four days. It made it possible to assess the existential, organizational, and relational complexities between stakeholders, who possess a range of expertise and professional skills, in this innovation cluster in the health care domain pertaining to aging and autonomy. It validated the practical and scientific interest of application of the FAcT-Mirror method in a type of cluster that is particularly complicated to induce into emergence and develop into sustainable operation, because of the diversity of the stakeholders and their expectations. This work demonstrates the usefulness of such an approach in the implementation of an action plan collaboratively formulated in a cluster and based on the articulation of fears, temptations, and attractions of the stakeholders of this cluster. This method is particularly effective in developing processes for convergence of conflicting ideas and for learning from one another for stakeholders who have little or no acquaintance with each other. It makes it possible to share risks and raise the stakeholders' awareness of performance leverage, constraints, and possible sources of difficulty, while reminding them of their responsibilities, especially in the case of the decision-makers. It also helps to raise the decision-makers' awareness of the resources that must be accumulated in order to attain the objectives that the cluster establishes. It demonstrates that as long as entities do not cooperate in a structured way, they cannot imagine the full potential of this cooperation and that, at the same time, the management and direction of this dynamic of cooperation via their goals, dangers, and values, requires a structured framework with permanent manpower. As long as this awareness is not achieved by all of the stakeholders, the cooperative interactions that might seem relevant to a given market may fail. The application of this method demonstrates that, following an original confidence-building exercise involving each stakeholder, an action plan can be produced collaboratively despite different interests and values. This method also allowed us to establish a joint representation of cluster processes and activities that can serve as a dashboard of indicators to control and measure the level of achievement of actions. It helped to identify and build cooperative work habits, best practices guidelines, and a relational ethic among stakeholders. Subsequent work will aim to model the set of these actions and assess their 
level of universality to clusters in general in order to provide a guide of best practices and feasibility to develop, direct, select, fund, and evaluate the actions of a cluster during its transition from emergence through development toward maturity. This work could be evidence of value creation by a cluster in a region, allowing public authorities to make long term investments of money in such structures. The validation of the application of the FAcT-Mirror method in the context of the Sol'iage innovation cluster opens the way for the development of this approach not only to clusters and inter-professional networks, but to any grouping of public organizations, private organizations, and/or associations that have a common motivation and wish to structure their cooperation. Finally, this method currently includes a simulator that measures the impact of implementation of future actions intended to structure the system studied. This development allows the construction of "What if" scenarios.

\section{References}

Bejean, S., Gaudreau, M., 1997. Concept de réseau et analyse des mutations récentes du système de santé. Revue d'économie industrielle, 81(1), 77-97.

Boly, V., Morel, L., Renaud, J., Guidat, C., 2000. Innovation in low tech SMBs: Evidence of a necessary Constructivist Approach. Technovation 20 (3), 161-168.

Boly, V., 2008. Ingénierie de l'innovation, organisation et méthodologies des entreprises innovantes. Lavoisier, Paris.

Ron A. Boschma, R. A., Ter Wal, A., 2007. Knowledge Networks and Innovative Performance in an Industrial District: The Case of a Footwear District in the South of Italy, Industry \& Innovation, 14(2), 177-199.

Calamet, L, Defélix, C., Picq, T., Retour, D., 2011. Inter-organizational Projects in French innovation Cluster : the Construction of Collaboration. International Journal of Project Management : article in press.

Clunet, 2008. Cluster Policy Guidelines Report. Pro Inno Europe, INNONETS CLUNET. http://proinno.intrasoft.be/ 
Cooke, P., Huggins, R., 2003. High Technology Clustering in Cambridge (UK) in: Sforzi F. (eds.), The Institutions of Local Development, IGU Series on Local Development, Ashgate. London.

D'Amour, D., San Martin Rodriguez, L., 2006. Collaboration among Health Professionals (II). Usefulness of a model, Rev Enferm, 29 (9), 47-52.

Depret, M.-H., Hamdouch A., 2009. Clusters, réseaux d'innovation et dynamiques de proximité dans les secteurs high-tech: une revue critique de la littérature récente. Revue d'économie industrielle, numéro spécial : la problématique des clusters : éclairages analytiques et empiriques, $\mathrm{n}^{\circ} 128$.

Fontagne, L., Koenig, P., Mayneris, F., Poncet, S., 2010. Clustering the Winners : The French Policy of Competitiveness Clusters. Centre d'études prospectives et d'informations internationales.

Forest, J., 2009. Penser la production de connaissances pour repenser la politique des clusters. Revue d'économie industrielle, numéro spécial: la problématique des clusters : éclairages analytiques et empiriques, $\mathrm{n}^{\circ} 128$.

Gaffard, J.-L., 2004. Développement local et globalisation. Revue de l'OFCE, n 94 .

Garcia, R., Calantone, R., 2002. A Critical Look at Technological Innovation Typology and Innovativeness Terminology: a Literature Review. The Journal of Product Innovation Management, 19, 110-132.

Gimbert, V., 2009. Les technologies pour l'autonomie : de nouvelles opportunités pour gérer la dépendance? Centre d'analyse stratégique.

Guilhon, B., Gianfaldoni, P., 1990. Chaînes de compétences et réseaux. Revue d'économie industrielle, 51(1), 97-112.

Hamdouch, A., 2008. La dynamique d'émergence et de structuration des clusters et réseaux d'innovation : revue critique de la littérature et éléments de problématisation. XLVème Colloque de l'ASRDLF. Rimouski, Québec.

Kooli-Chaabane,H., Camargo, M., Boly, V., Yannou, B., 2008(a). Modeling Technology Transfer Process: Proposition of a qualitative and quantitative observation approach. EUROMOT, Nice, France. 
Kooli-Chaabane, H., Camargo, M., Boly, V., Yannou, B., 2008(b). Updating current Practices in the Technology Transfer Management Process: Overview from Macro to Micro Point of View. IAMOT, Dubai, UAE.

Lartigue, S., Soulard, O., 2008. Clusters mondiaux : regards croisés sur la théorie et la réalité des clusters. Identification et cartographie des principaux clusters mondiaux. Institut d'Aménagement de la région d'Ile de France. Paris.

Le Cardinal, G., Guyonnet, J.-F., Pouzoulic, B., 1997. La dynamique de la confiance. Dunod, Paris.

Le Cardinal, G., Guyonnet, J.-F., Pouzoullic, B., Rigby, J., 2001. Theory and Methodology. Intervention Methodology for Complex Problems: The FAcT-Mirror Method. European journal of operational research. 132, 694-702.

Le Moigne, J.-L., 1999. La modélisation des systèmes complexes. Dunod, Paris.

Lendel, I., 2006. The Healthcare Cluster in the Cleveland-Elyria-Mentor MSA, 2000-2005. Technical Report. The Center for Economic Development Maxine Goodman Levin College of urban Affairs. http://urban.csuohio.edu

OECD (Organisation for Economic Co-operation and Development), 2005. Oslo Manual. The measurement of scientific and technological activities. Proposed guidelines for collecting and interpreting technological innovation data. European Commission. Eurostat, Paris.

OECD, 2001. Innovative Clusters: Drivers of Innovation System. Paris.

Porter, M., 1998. On competition. Harvard Business School Press, Boston.

Ritter, T., Gemunden,H., 2003. Network Competence: Its Impact on Innovation Success and its Antecedents. Journal of Business Research., 56(9), 745-755.

Rosenfeld, S., 2002. Just Clusters: Economic Development Strategies that Reach More People and Places. The collaborative result of a two-day intensive meeting of 23 practitioners, policy makers, and researches, this report refocuses cluster strategy on equity. Regional Technology Strategies, Carrboro, NC. http://rtsinc.org/publications/index.html

Schindler, A., Bocquet, J.-C., Dudezert, A., 2007. Systemic Approach as a Multi-Criteria Design method: Healthcare R\&D Centre Application. ICED'07, Paris, France. 
Weil, T., Glaser, A., Lefebvre P., Pallez, F., Gallie, E.P., Merindol, V., 2010. Why are good comparative studies of networks so rare? Practical lessons from a study on clusters. EGOS, Lisbon.

Yoshida, K., Nakanishi, M., 2005. Factors underlying the Formation of Industrial Clusters in Japan and Industrial Cluster Policy : A Quantitative Survey. JETRO Discussion Papers (Institute of Development Economies), 45.

Zimmer B., 2012. Structuration d'un cluster d'innovation : application aux projets d'innovation en gérontechnologie, thèse de doctorat, Ecole Centrale Paris, $N^{\circ} 2012$ ECAP0023. 